This item was submitted to Loughborough's Research Repository by the author.

Items in Figshare are protected by copyright, with all rights reserved, unless otherwise indicated.

\title{
Still life in motion: The performance of time in video painting
}

PLEASE CITE THE PUBLISHED VERSION

https://doi.org/10.1080/13528160701363457

PUBLISHER

(c) Taylor \& Francis

VERSION

AM (Accepted Manuscript)

\section{PUBLISHER STATEMENT}

This work is made available according to the conditions of the Creative Commons Attribution-NonCommercialNoDerivatives 4.0 International (CC BY-NC-ND 4.0) licence. Full details of this licence are available at: https://creativecommons.org/licenses/by-nc-nd/4.0/

\section{LICENCE}

CC BY-NC-ND 4.0

\section{REPOSITORY RECORD}

Bolewski, Christin. 2019. "Still Life in Motion: The Performance of Time in Video Painting". figshare. https://hdl.handle.net/2134/36506. 


\section{Christin Bolewski Loughborough School of Art and Design}

\section{„Still life in motion“- the performance of time in video painting}

„Still life in motion“ is an artistic project, which connects the tradition of painting with the moving image to create an object of modern video art. It reworks traditional themes and ideas and explores new artistic boundaries and styles of representation by using High Definition video technology. It is a development of a new form of contemporary video expression called "video painting“. One of the most interesting questions it poses is, how time is performed in these video paintings.

The absence of the dimension of time seems to be particularly evident in painting and even more in an arrangement of still objects. Still life painting has been an ongoing developed topic in the history of fine art practice. It can be a banal or highly symbolic representation of objects, as well as a visual self-reflection of the evolution of painting aesthetics and practice. But not to forget: the presence of the absence of time is often the subliminal dominant subject of still life! There are the beautifully arranged flowers of a bouquet, which, in fact, grow in different seasons, or there is the removed, left out person, whose traces the viewer can only find in the remains of a meal on a table. Often there is a slice of lemon nearly falling out of the frame, and there is a fly in the center of the painting waiting to be discovered. It irritates the perception of the viewer, because he cannot decide for a moment, whether it is part of the picture or sits just on the linen moving away within the next second [1]. All of these examples show, that time is an important issue of still life, and therefore, this genre seems to be specially enabled to overcome transitoriness and connect to modern time-based media expression.

The use of new technologies in visual and performance arts has almost inevitably led to the blurring of established definitions, roles, and taxonomies of art. New video technolgies constantly change the aesthetic capabilities of the moving image, and latest developments in High Definition Video and flatsceen displays provide a high-quality platform for the presentation of the moving image. This technological setting creates the new ambient video genre of the video painting. As Jim Bizzocchi, an artist and Assistant Professor at Simon Fraser University's School of Interactive Arts and Technology, Canada describes, "video paintings are video works, which are presented on LCD panels. They are wall-mounted in the same manner as traditional paintings. Content in this emergent form is designed to work at all times as either a highly aware foregrounded experience or as passive background. It can act as the focus of attention, or it can be totally overlooked and submerged within the surrounding environment. Like traditional paintings, video paintings hang on the wall to be viewed or ignored - depending on individual viewer preference in the moment. Therefore, a video painting emerges as a supremely pictorial form. It creates a visual aesthetic, which relies on high visual impact, the subtle manipulation of image, multiple layers, and the play of gradual, complex transitions. It is a smooth temporal flow, always changing, but never too quickly. The piece is an exploration of concepts of ambience, time, and the liminality of image and of narrative“" [2].

"Still life in motion" explores this new technological setting: The canvas gets replaced by a large high resolution flatscreen expanded by perspectives of time and space, reconstructing and deconstructing the issues of the still life genre at the same time. Using the possiblities of modern digital video processing and animation techniques, the motif gets fragmented through a collage of established traditional film codes, revealing techniques of cubistic painting culture (referring to time and space perspective). Time is explored as an aesthetic variable and is treated and performed differently. First the slow decay of a still life is filmed over a period of several weeks from different shot sizes and perspectives. Then the real-time video and sound footage gets processed by fast motion effects to speed up the rotting process to a visible level. During the editing process several stages of the rotting process get arranged in a narration determined by the movement within the image and the accompanying sound patterns and rhythms. Time is heavily manipulated in this process and emerges as the main element of the work. Different parts of the image are arranged running simultaneously forward and backward, in fast motion, at different speed, or being looped - the still life starts to 
"breathe". Growth gets confronted with destruction, aesthetic beauty with rotten ugliness.

To create an analogy to cubistic painting practice and to deliver different perspectives and viewpoints simultaneously within one image, digital techniques of collage, split-screen, and video layering are applied. Instead of presenting the different shot sizes and perspectives in the linear fashion common in temporal television montage, the concept of spatial montage within the frame is used. This is common practice in traditional cinematic montage, because the larger and richer screen of cinema prefers the painterly beauty of the carefully composed and detailed image to deliver an experience where the viewer can explore the image by himself and his eyes can wander around and pick up, whatever he wants. The increased picture size and quality of the video painting supports this pictorial cinema as well, and subtle details can be observed much better. More time is needed to explore these rich images, and editing pace needs to slow down. This is in opposition to the temporal acceleration in contemporary video narration. Television screens are small and deliver a fuzzy image. Therefore, story tends to be presented and staged through sequencing of tighter images rather than through the visual dynamics of a single rich image - temporal montage displaces spatial expressivity [2]. The standard viewer is accustomed to the fast speed of television narratives, and his ability to take in visual information has increased enormously with the fast editing norm. The ambient video painting rediscovers the use of the cinematic composition-indepth, and a slow editing pace using more layered transition instead of the hard video cut. This means, that the dimension of time in video narration, which has been divided up and sequenced in smallest units of fast moving and continuously changing key visuals, can now return to a slow flow of evolutionary nature. "To see time go by" Is a minimalist stance, which has been explored earlier in the 60's by avant-garde filmmakers such as Andy Warhol. His movie "Empire" [3] consists of the epic stationary 8 hour shot of the Empire State Building and explores the possibilities of the extremely long take.

The experience of real-time and the sensation of reality are fundamental characteristics of High Definition Video as a result of the more realistic and detailed image. "Telepresence" is an aesthetic concept, which plays with the simulation of reality and the performance of realtime events. More precise is the term "transparent telepresence", which describes the experience of being fully present at a live real world location remote from one's own physical location. Someone experiencing transparent telepresence would be able to behave and receive stimuli as though at the remote site and would experience real-time events [4]. High Definition video is privileged to perform real-time events, and therefore nature sequences and the play of landscape and skyscape are very suitable topics. "Still life in motion" does not perform real-time, but like most video paintings, it has a slow flow of manipulated time, which provokes irritation in the viewer's perception, whether he sees a real, still, or moving image. Like the still life painting, it can confuse the viewer, whether the fly will move away or not - in reality or on the screen. This effect gains the necessary impact to catch the viewer's foreground attention. Due to the wall-mounted presentation of video paintings, it depends on the individual preference of the viewer, whether it gains full attention or has to work as passive background. Therefore, the video painting has to face different tasks. It must work well on first viewing, be interesting enough to keep the viewers full attention, and sustain interest over multiple iterations, while it is repeated endlessly [2]. The ideal viewing situation is one, where the viewer can sit on a bench or a couch to contemplate the video painting. A meditative ambient atmosphere must be provided to seduce the viewer to the longer and closer examination, and the viewer's perception of his own individual time flow is another aspect to look at: The video painting invites the viewer to escape from the omnipresent fast flow of rapidly changing moving images and to increase his own visual sensibility. It is an opportunity to calm down from the fast speed of contemporary modern life and to rediscover the slow flow of passing time.

The project „still life in motion“ is curated by Marcel Odenbach, an international established media artist of highest rank of the first generation of German video artists. It is realized in cooperation with SONY Germany as part of the Braviamotionart project, which stands in the long tradition of SONY to support video artists using new technology to explore new artistic boundaries and styles of representation. Futher information about the project and other participating artist can be found at http://www.sony.de/braviamotionart 
Technical Information "Still life in motion"

Single screen video installation

HDV, Color 8,25 min, Sound Stereo 1+2, recorded and mastered on HDV, ( C Christin

Bolewski 2005

Distributed as limited art edition DVD by SONY Germany $\mathrm{GmbH}$

http://www.sony.de/braviamotionart

References

[1] Grohé, Stefan. Stillleben im Goldenen Zeitalter der holländischen Malerei. Meisterwerke der holländischen Malerei. München: Prestel Verlag, 2004. (free translation of the German text).

[2] Bizzocchi, Jim. Video as Ambience: Reception and Aesthetics of Flat-Screen Video Display. Available at: http://www. dadaprocessing.com; accessed 1 August 2006.

[3] Warhol, Andy. Empire. Film, 1964.

[4] Definition by the Transparent Telepresence Research Group (TTRG). Available at: http://telepresence.dmem.strath.ac.uk/telepresence.htm; accessed 13 May 2006 